\title{
FOLIAR APPLICATION OF DIANELLA ENSATA, AMBROSIA DUMOSA AND MORINGA OLEIFERA IMPROVED BARLEY GROWTH AND YIELD TRAITS UNDER DROUGHT STRESS
}

\author{
ALGHABARI, F. \\ Department of Arid Land Agriculture, Faculty of Meteorology, Environment \& Arid Land \\ Agriculture, King Abdulaziz University, P.O. Box 80208, Jeddah 21589, Saudi Arabia \\ (e-mail: falghabari@hotmail.com; phone: +96-655-827-7766)
}

(Received $26^{\text {th }}$ Feb 2020; accepted $7^{\text {th }}$ Jul 2020)

\begin{abstract}
Barley (Hordeum vulgare L.) is one of the major cereal crops cultivated in Saudi Arabia. A pot experiment was performed to estimate the effect of drought stress on barley crop while natural plants extract were used as a management strategy. The experiment was laid out in a completely randomized design with three repetitions. Pots grown barley were thinned to three plants per pot and allowed to grow undisturbed until the start of reproductive stage. Aqueous extract of flax liliy; Dianella ensata, burroweed; Ambrosia dumosa and drumstick tree; Moringa oleifera were used along with the control. Drought stress treatments were 40\%, 60\% and 100\% field capacity. The application of Dianella ensata and Moringa oleifera produced double number of productive tillers and 30-38\% recovery for number of spikelets per spike. Severe drought stress reported a substantial decrease $(-31 \%)$ in number of grains per spike and 1000 grain weight while the application of Moringa oleifera has achieved 28\% higher number of grains per spike and 24\% higher 1000 grain weight. The application of Moringa oleifera also reported an increase of $28-35 \%$ in leaf area and chlorophyll content. On contrary to other traits, a positive correlation exists between the drought stress and root length.
\end{abstract}

Keywords: drought stress, cereal crop, drought mitigation, field capacity, Hordeum vulgare

\section{Introduction}

The global population is continuously increasing and the growth may reach up to 9.7 billion by 2050, so global agriculture is supposed to produce $70 \%$ more food in future. In addition, there are other fields for world agriculture to fight, to try to eliminate increasing poverty and hunger, and to restore the diminishing natural agricultural resources as was called for by the food and agriculture organization (FAO, 2009; Bourne, 2009). Crop production is not coping with the increasing demands for food, and this is due to many stressing factors (Alghabari et al., 2015; Fahad et al., 2017, 2018). Scarce rainfall in arid regions is considered the main reason for low crop production, so efforts are needed to manage this problem. Policies should be directed toward planting of drought resistant salt tolerant crops, and crops with short duration together with the application of growth promoting substances (Ihsan et al., 2016a). Naeem et al. (2018) reported a positive role of calcium in drought stress management in maize crop. Daur et al. (2018) studied the positive role of rhizobacteria isolated from the roots of various plants of Saudi Arabia on alfalfa growth and yield.

The annual grain crop barley (Hordeum vulgare L.) is one of the cereal crops famous for cultivation in arid and saline regions (Alghabari and Ihsan, 2018). It contains high percentages of carbohydrates, and rich in minerals and vitamins. Barley is considered one of the valuable food resources, and can be used as whole grain as an animal feed for goats, sheeps or processed and making different food products and infant foods. Barley can succeed in arid areas with limited water suuply. Plant growth and yield decreased under drought stress (Fenta et al., 2014), and this reduction in growth and yield is 
attributed to changes in the physiological and phnological parameters of the plant due to the scarcity of water (Ihsan et al., 2016b). There is a continuous reduction in soil water supplies throughout the world, and this is suggested to cause losses in plant production all over the world up to $30 \%$ by 2025 , compared to the current yields (Zhang, 2011). When planting crops under arid land conditions they face water deficit stress throughout their growth cycle especially at anthesis (Ihsan et al., 2016b; Fahad et al., 2017).

On the other hand climatic conditions are continuously changing, and these changes had negative impact on crop growth and yield due to escalation in drought, salinity and heat stresses intensity. Of these stresses drought can be considered the most devastating abiotic stress (Alghabari et al., 2015; Alghabari and Ihsan, 2018). Drought stress problem increased tremendously in field crops due to climate change, anthropogenic activities, bad crop choice, improper use of land and low irrigation efficiency. Production of new genetically bred drought tolerant crop varieties will help in solving problem of agriculture in arid regions. Plant growth promoting extracts of natural plants would be another suitable option due to their safety and low prices.

In nature there are many drought stress tolerant wild plants with many potentialities that can be used with crop plants (Abbasi et al., 2009), for they represent sources of number of biochemicals which have growth stimulatory characters. There is a limited work on the use of wild plant species as drought stress ameliorators in field crops. Saudi desert is rich in wild flora and efforts should be exerted to discover their growth promoting potential in detail. Drought stress arises from diminish in fresh water resources, reduction in annual rainfall, and inability in storing rain water and generally features of aridity of the region. Drought stress causes a serious damage to field crops particularly at germination and flowering stages. Planting of barley is preferred in arid regions because it is considered a short duration crop and its water requirement is very low, and in spite of that barley crop growth faces severe drought cycles resulting in minimum seed germinaion and final grain yield.

The current study was performed to estimate the impact of drought stress on barley growth, yield and root characteristics. The wild desert plant species water extract was used as a drought stress management strategy. The wild desert plants; Dianella ensata, Ambrosia dumosa, Moringa oleifera Lam were compared for drought stress regulation in pot sown barley crop.

\section{Materials and Methods}

\section{Layout of the experiment}

A model pot experiment was conducted to evluate the response of barley (Hordeum vulgare) crop against drought stress and its management through foliar application of natural plants extract (NPE). The experiment was performed at the Hada Al-Sham Agricultural Research Station of King Abdulaziz University Jeddah, Kingdom of Saudi Arabia during 2018. Three NPEs (Flax liliy; Dianella ensata, burro-weed; Ambrosia dumosa, drumstick tree; Moringa oleifera) were used along with the control. These plants were selected based on their adaptibility to arid environment of Saudi Arabia and their properties to withstand drought stress. Drought stress treatments were applied as $40 \%, 60 \%$ and $100 \%$ of field capacity (FC) at the onset of reproductiove stage. The experiment was layed out in a completely randomised design with a factorial arrangements. There were three repetitions for each treatment, and a total number of 36 
experimental units were used in this experiment. The used NPE, FC and sequence of treatments are presented in Table 1.

Table 1. Tabulated presentation of treatments; natural plant extract (NPE) and field capacity (FC)

\begin{tabular}{c|c|c|c}
\hline Sr. No & Treatments & Common name & Botanical name \\
\hline & \multicolumn{3}{|c}{ Natural Plants Extract (NPE) } \\
\hline 1 & NPE1 & Control & Water \\
2 & NPE2 & Flax lily & Dianella ensata \\
3 & NPE3 & burro-weed & Ambrosia dumosa \\
4 & NPE4 & drumstick tree & Moringa oleifera Lam \\
\hline & \multicolumn{3}{|c}{ Drought stress (FC) } \\
\hline 1 & FC1 & $100 \%$ & No stress \\
2 & FC2 & $60 \%$ & Moderate stress \\
3 & FC3 & $40 \%$ & Severe stress \\
\hline
\end{tabular}

\section{Pots preparation}

Soil collected from the agriculture fields of Hada Al-Sham research station was mixed with farmyard manure (2:1 ratio) to improve the soil physio-chemical and biological properties of the growing medium. Soil field capacity was determined by using gravimetric method. The irrigation water ratios were $40 \%$ FC extreme drought stress, $60 \%$ FC moderate drought stress and $100 \%$ FC no drought stress were considered as control (non-stressed). The pots were $30 \mathrm{~cm}$ tall and $22 \mathrm{~cm}$ wide. Each pot was filled with three $\mathrm{kg}$ of growth medium. Sowing of barley seeds was carried out on second week of February. At least ten healthy seed (variety; Sanober-96) were sown in each pot.

\section{Treatments application}

After 15 days of germination, the number of plants were thinned to three plants per pot and excessive plants were removed. The chemical fertilizer NPK was applied at a rate of $4 \mathrm{~g}: 2 \mathrm{~g}: 2 \mathrm{~g}$ per pot dissolved with irrigation water. Fertilizers were applied in two split doses at 30 days time interval starting from tillering. Field capacity level of each treatment was adjusted and the exact amount of water was added to each pot under each stress treatment. The soil FC was determined according to the gravimetric method (Alghabari and Ihsan, 2018). The pots were weighted at three days interval and manually irrigated to maintain the required FCs.

\section{Preparation of wild plants extract}

Three wild plants (Dianella ensata, Ambrosia dumosa, Moringa oleifera Lam) were used to study their response against drought stress in a pot experiment. Two kg air dried biomass of each plant was ground to fine powder and soaked in 5 liters of water for 80 minutes. The mixture was boiled for 3 hours at $100{ }^{\circ} \mathrm{C}$ to obtain the concentrate solution, which was then cooled and saved in plastic bottles for further use (Yasmeen et al., 2012). 


\section{Application of wild plants extract}

Drought stress was started at the onset of reproductive stage (initiation of spike) and continued untill the maturity stage. The NPEs were exogenously sprayed after diluting the extract 10 times. The NPEs were applied at three times before start of drought stress -10 and after drought stress 20 and 40 days of drought stress application. Plants were harvested at maturity and the following parameters were measured.

\section{Data collection}

Data were collected from each pot separately at the time of the harvest of the experiment. Data collection included different growth, yield and root characteristics. Plant height $(\mathrm{cm})$ was measured from the base of the plant to the tip of the spike through a measuring scale. The number of spikes per plant were manually calculated through counting the number of productive tillers. The plant weight was measured from each plant excluding the root biomass and presented in grams. Single spike weight was measured from the spike of the primary tiller. The spike length were measured by following the procedure adoted for the measurement of the plant height. The number of spikelets per spike and number of grains per spike were manually counted from each spike. The 1000 grain weight was recorded by weighting the 100 grains and multiplying it with 10 for each treatment. The flag leaf area was measured through leaf scanner and chlorophyll content through chlorophyll meter. Both characters were measured before the harvest of the plants but after completing the application of treatments. The root dynamics were measured as root length, root fresh and dry biomass accumulation. A measuring scale was used to measure the root length from the base of the stem to the tip of the root. Root fresh weight was taken with the help of digital balance. For the measurement of root dry weight, the fresh root samples were transferred to hot air oven for 72 hours. The temperature was set at $70{ }^{\circ} \mathrm{C}$. The root dry weight was measured after uniform drying of all the root samples.

\section{Statistical analysis}

It was a two factor experiment; 1) drought stress and 2) natural plants extract. Drought stress consisted of three levels while plant extracts have four levels. The total number of treatments were twelve. The experiment was run in a completely randomised design with three repetitions. Data were statistically analyzed by using analysis of variance under SAS software, and least significant difference (LSD) test was used to determine and compare treatment means to estimate their significance. Figures are drawn by using MS excel software. Verticle lines on the figures represent the standard error bars.

\section{Results}

\section{Growth traits}

Table 2 represents the data for the barley growth characteristics. The effect of natural plants extract was highly significant $(\mathrm{p} \leq 0.01)$ for barley plant height, number of spikes per plant and single plant weight. The effect of drought stress was significant $(\mathrm{p} \leq 0.05)$ for plant height and plant weight while non-significant $(\mathrm{p} \geq 0.05)$ for number of spikes per plant. The interaction of natural plants extract and drought stress were highly significnt $(\mathrm{p} \leq 0.01)$ for plant height and number of spikes per plant while significant $(\mathrm{p} \leq 0.05)$ for single plant weight. 
Table 2. Barley plant height (cm) and number of spikes/plant as affeted by the foliar applied natural plant extracts (NPEs) and drought stress (FC)

\begin{tabular}{c|ccc|ccc|ccc}
\hline \multirow{2}{*}{$\begin{array}{c}\text { Plant } \\
\text { extracts }\end{array}$} & \multicolumn{2}{|c|}{ Plant height (cm) } & \multicolumn{3}{c|}{ Number of Spikes/plant } & \multicolumn{3}{c}{ Plant weight (g) } \\
\cline { 2 - 9 } & FC-1 & FC-2 & FC-3 & FC-1 & FC-2 & FC-3 & FC-1 & FC-2 & FC-3 \\
\hline NPE 1 & $47.00 \mathrm{f}^{*}$ & $44.17 \mathrm{j}$ & $40.00 \mathrm{k}$ & $4 \mathrm{~b}$ & $3 \mathrm{c}$ & $2 \mathrm{~d}$ & $8.69 \mathrm{~d}$ & $6.20 \mathrm{~g}$ & $4.85 \mathrm{i}$ \\
NPE 2 & $50.37 \mathrm{~b}$ & $48.19 \mathrm{e}$ & $45.12 \mathrm{~h}$ & $5 \mathrm{a}$ & $4 \mathrm{~b}$ & $4 \mathrm{~b}$ & $10.32 \mathrm{~b}$ & $7.92 \mathrm{e}$ & $5.63 \mathrm{~h}$ \\
NPE 3 & $49.33 \mathrm{c}$ & $47.32 \mathrm{f}$ & $44.71 \mathrm{i}$ & $5 \mathrm{a}$ & $4 \mathrm{~b}$ & $3 \mathrm{c}$ & $9.66 \mathrm{c}$ & $7.01 \mathrm{f}$ & $5.21 \mathrm{~h}$ \\
NPE 4 & $52.25 \mathrm{a}$ & $48.63 \mathrm{~d}$ & $46.13 \mathrm{~g}$ & $5 \mathrm{a}$ & $4 \mathrm{~b}$ & $4 \mathrm{~b}$ & $11.45 \mathrm{a}$ & $8.12 \mathrm{de}$ & $6.10 \mathrm{~g}$ \\
NPE & $* *$ & & & $* *$ & & & $* *$ & & \\
FC & $*$ & & & ns & & & $*$ & & \\
NPE $\times$ FC & $* *$ & & & $* *$ & & & $*$ & & \\
LSD & 0.35 & & & 0.45 & & & 0.56 & & \\
\hline
\end{tabular}

*; figures differing in letters are statistically significant at $\mathrm{p} \leq 0.05, * *$; significant at $\mathrm{p} \leq 0.01$, ns; non-significant, LSD; least significant difference. NPE 1; Water, NPE 2; Dianella ensata, NPE 3; Ambrosia dumosa, NPE 4; Moringa oleifera Lam

Drought stress displayed a negative effect on plant growth characteristics and the severity of the negative effect increases with the increase in the level of drought stress. On contrary, the application of natural plants extract has ammeliorated the negtive effects of drought stress and improved plant growth characteristics. The maximum plant height was recorded under normal growth conditions with the application of Moringa oleifera leaf extract. Similarly, this treatment reported the maximum plant height at moderate and severe drought stress as compared to control and other natural plants extract treatments. The foliar application of Moringa oleifera leaf extract reported $11 \%$ increase in plant height under normal condition and $15 \%$ at $40 \%$ field capacity as compared to control. Number of spike per plant were less affected by the application of natural plants effect and field capacity for $100 \%$ FC and $60 \%$ FC while the effect was more significant at $40 \%$ FC. The foliar application of Dianella ensata and Moringa oleifera leaf extracts produced a double number of productive tillers as compared to control at $40 \%$ FC. The plant weight has sharply decreased with the increase in drought stress levels. The $40 \%$ FC exhibited a $44 \%$ decrease in plant weight as compared to $100 \%$ FC. The application of Moringa oleifera leaf extract presented a $26 \%$ recovery in plant weight at severe drought stress ( $40 \%$ FC) when compared to control.

\section{Spike characteristics}

Spike related characters such as single spike weight, spike length and number of spikelets per spike were presented in Table 3. The effect of natural plants extract was highly significant $(\mathrm{p} \leq 0.01)$ for single spike weight and spike length while significant $(p \leq 0.05)$ for number of spikelets per spike. The effect of drought stress was highly significant $(\mathrm{p} \leq 0.01)$ for single spike weight while significant $(\mathrm{p} \leq 0.05)$ for spike length and number of spikelets per spike. The interaction of natural plants extract and drought stress was highly significant $(\mathrm{p} \leq 0.01)$ for single spike weight and number of spikelets per spike while non-significant $(\mathrm{p} \geq 0.05)$ for the spike length. 
Table 3. Barley spike characterisitics as affected by drought stress $(F C)$ and natural plant extract (NPE) foliar application

\begin{tabular}{|c|c|c|c|c|c|c|c|c|c|}
\hline \multirow{2}{*}{$\begin{array}{c}\text { Plant } \\
\text { extracts }\end{array}$} & \multicolumn{3}{|c|}{ Spike weight (g) } & \multicolumn{3}{|c|}{ Spike length (cm) } & \multicolumn{3}{|c|}{ No. of Spikelets per spike } \\
\hline & FC-1 & FC-2 & FC-3 & FC-1 & FC-2 & FC-3 & FC-1 & FC-2 & FC-3 \\
\hline NPE 1 & $1.80 \mathrm{~b}$ & $1.20 \mathrm{~b}$ & $0.68 \mathrm{c}$ & $6.11 \mathrm{~d}$ & $5.65 \mathrm{c}$ & $4.11 \mathrm{c}$ & $41.15 \mathrm{c}$ & $35.23 \mathrm{e}$ & $25.21 \mathrm{~h}$ \\
\hline NPE 2 & $2.43 \mathrm{a}$ & $2.05 \mathrm{a}$ & $1.66 \mathrm{~b}$ & $6.40 \mathrm{~b}$ & $5.95 \mathrm{~b}$ & $4.61 \mathrm{~b}$ & $43.78 \mathrm{a}$ & $39.78 \mathrm{~cd}$ & $32.89 \mathrm{f}$ \\
\hline NPE 3 & $2.04 \mathrm{a}$ & $1.78 \mathrm{~b}$ & $1.40 \mathrm{~b}$ & $6.18 \mathrm{c}$ & $5.78 \mathrm{~b}$ & $4.55 \mathrm{~b}$ & $42.22 \mathrm{~b}$ & $38.44 \mathrm{~d}$ & $30.78 \mathrm{~g}$ \\
\hline NPE 4 & $2.92 \mathrm{a}$ & $2.36 \mathrm{a}$ & $1.71 \mathrm{~b}$ & $6.80 \mathrm{a}$ & $6.05 \mathrm{a}$ & $4.98 \mathrm{a}$ & $44.25 \mathrm{a}$ & $40.21 \mathrm{c}$ & $34.80 \mathrm{e}$ \\
\hline NPE & $* *$ & & & $* *$ & & & $*$ & & \\
\hline $\mathrm{FC}$ & $* *$ & & & $*$ & & & * & & \\
\hline $\mathrm{NPE} \times \mathrm{FC}$ & $* *$ & & & $\mathrm{~ns}$ & & & $* *$ & & \\
\hline LSD & 0.98 & & & 0.20 & & & 1.05 & & \\
\hline
\end{tabular}

*; figures differing in letters are statistically significant at $\mathrm{p} \leq 0.05, * *$; significant at $\mathrm{p} \leq 0.01$, ns; nonsignificant, LSD; least significant difference. NPE 1; Water, NPE 2; Dianella ensata, NPE 3; Ambrosia dumosa, NPE 4; Moringa oleifera Lam

The application of Moringa oleifera leaf extract procured the maximum spike weight and that was statistically non-significant to other three natural plants extract treatments at $100 \%$ FC. Spike weight, spike length and number of spikelets per spike were gradually decreased with the application of drought stress irrespective of the application of natural plants extract. At moderate drought stress the application of Moringa oleifera leaf extract reported $96 \%$ improvement in spike weight as compared to control. The application of Moringa oleifera leaf extract displayed $7 \%$ and $21 \%$ recovery in spike length at moderate and severe drought stress levels as compared to the control. The $40 \%$ FC confirmed $39 \%$ decrease in number of spikelets per spike as compared to $100 \%$ FC. The application of Dianella ensata and Moringa oleifera plant extracts demonstrated $30 \%$ and $38 \%$ recovery for number of spikelets per spike as compared to control at severe drought stress respectively.

\section{Grain attributes}

Table 4 presented the data of number of grains per spike and 1000 grain weight. Both traits are exeedingly important and directly contribute in final yield. The main effects of natural plant extracts and drought stress were significant $(\mathrm{p} \leq 0.05)$ for number of grains per spike and 1000 grain weight while their interaction was highly significant $(p \leq 0.01)$. The application of moderate drought stress at $60 \%$ FC level presented a slighter decrease (12-14\%) while the severe drought stress level at $40 \%$ FC reproted a substantial decrease (28-31\%) in number of grains per spike and 1000 grain weight, respectively. Moringa oleifera reported the maximum number of grains per spike and 1000 grain weight and it was followed by the Dianella ensata that was the $2^{\text {nd }}$ best treatment for the mitigation of drought stress on barley grain attributes. Under severe drought stress the application of Moringa oleifera leaf extract achieved 28\% higher number of grains per spike and 24\% higher 1000 grain weight as compared to control. 
Table 4. 1000 grain weight $(\mathrm{g})$ and plant weight $(\mathrm{g})$ as affected by drought stress $(F C)$ and natural plant extract (NPE) foliar application

\begin{tabular}{c|ccc|ccc}
\hline \multirow{2}{*}{$\begin{array}{c}\text { Plant } \\
\text { extracts }\end{array}$} & \multicolumn{2}{|c|}{ Number of grains per spike } & \multicolumn{3}{c}{ 1000 grain weight (g) } \\
\cline { 2 - 7 } & FC-1 & FC-2 & FC-3 & FC-1 & FC-2 & FC-3 \\
\hline NPE 1 & $24.12 \mathrm{e}$ & $21.21 \mathrm{~h}$ & $17.22 \mathrm{j}$ & $36.45 \mathrm{c}$ & $31.30 \mathrm{f}$ & $25.16 \mathrm{~h}$ \\
NPE 2 & $27.65 \mathrm{~b}$ & $24.43 \mathrm{e}$ & $21.32 \mathrm{~h}$ & $38.67 \mathrm{a}$ & $35.22 \mathrm{~d}$ & $30.32 \mathrm{~g}$ \\
NPE 3 & $26.54 \mathrm{c}$ & $23.67 \mathrm{f}$ & $20.14 \mathrm{i}$ & $38.25 \mathrm{~b}$ & $34.36 \mathrm{e}$ & $29.90 \mathrm{~g}$ \\
NPE 4 & $28.33 \mathrm{a}$ & $25.44 \mathrm{~d}$ & $22.05 \mathrm{~g}$ & $38.98 \mathrm{a}$ & $36.30 \mathrm{c}$ & $31.18 \mathrm{f}$ \\
NPE & $*$ & & & $*$ & & \\
FC & $*$ & & & $*$ & & \\
NPE $\times$ FC & $* *$ & & & $* *$ & & \\
LSD & 0.32 & & & 0.55 & & \\
\hline
\end{tabular}

*; figures differing in letters are statistically significant at $\mathrm{p} \leq 0.05, * *$; significant at $\mathrm{p} \leq 0.01$, ns; nonsignificant, LSD; least significant difference. NPE 1; Water, NPE 2; Dianella ensata, NPE 3; Ambrosia dumosa, NPE 4; Moringa oleifera Lam

\section{Flag leaf area and chlorophyll content}

Flag leaf attributes are presented in Figure 1. Flag leaf area and chlorophyll content play an important role in active photosynthesis and carbon assimilation. Effect of natural plants extract, drought stress and their interaction was significant $(\mathrm{p} \leq 0.05)$ for both flag leaf area and chlorophyll content. The flag leaf area ranged from $25-30 \mathrm{~cm}^{2}$ for unstressed pots to $17-22 \mathrm{~cm}^{2}$ for severe drought stressed pots. The values of leaf chlorophyll content ranged from $7-8.9 \%$ for unstressed pots to $4.6-6.2 \%$ for severe drought stressed pots. The application of Moringa oleifera reported an increase of $28-35 \%$ in leaf area and chlorophyll content at severe drought stress as compared to control, respectively.
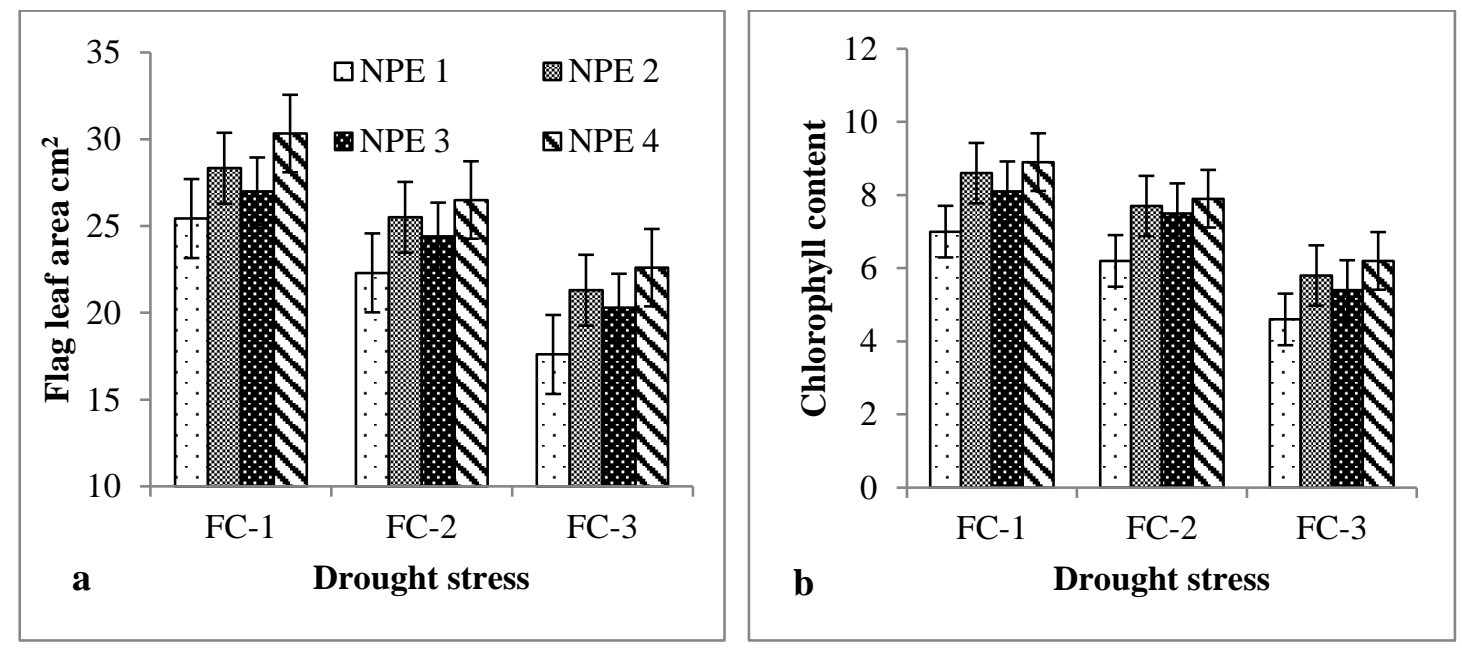

Figure 1. Effect of drought stress and natural plant extract (NPE) on flag leaf area and chlorophyll content measured two weeks after the application of treatments. NPE 1; Water, NPE 2; Dianella ensata, NPE 3; Ambrosia dumosa, NPE 4; Moringa oleifera Lam. FC is field capacity that represent different levels of drought stress 


\section{Root dynamics}

Root characteristics such as root length, root fresh and dry weight are measured at plant harvest and data is presented in Figure 2. The effect of natural plants extract, drought stress and their interaction was significant $(\mathrm{p} \leq 0.05)$ for root characteristics. Drought stessed displayed a negative effect on root fresh and dry weight while it improved the root length. The effect of natural plant extract was also positive for root length and fresh and dry biomass accumulation. The 40\% FC ensured the maximum root length with an increase of $45 \%$ as compared to $100 \%$ FC. At sever drought, the application of natural plants extract reported an increase of 71-62\% in root fresh and dry weight as compared to control. Moringa oleifera and Dianella ensata contributed significantly for the mitigation of drought stress and improvement in root characteristics.

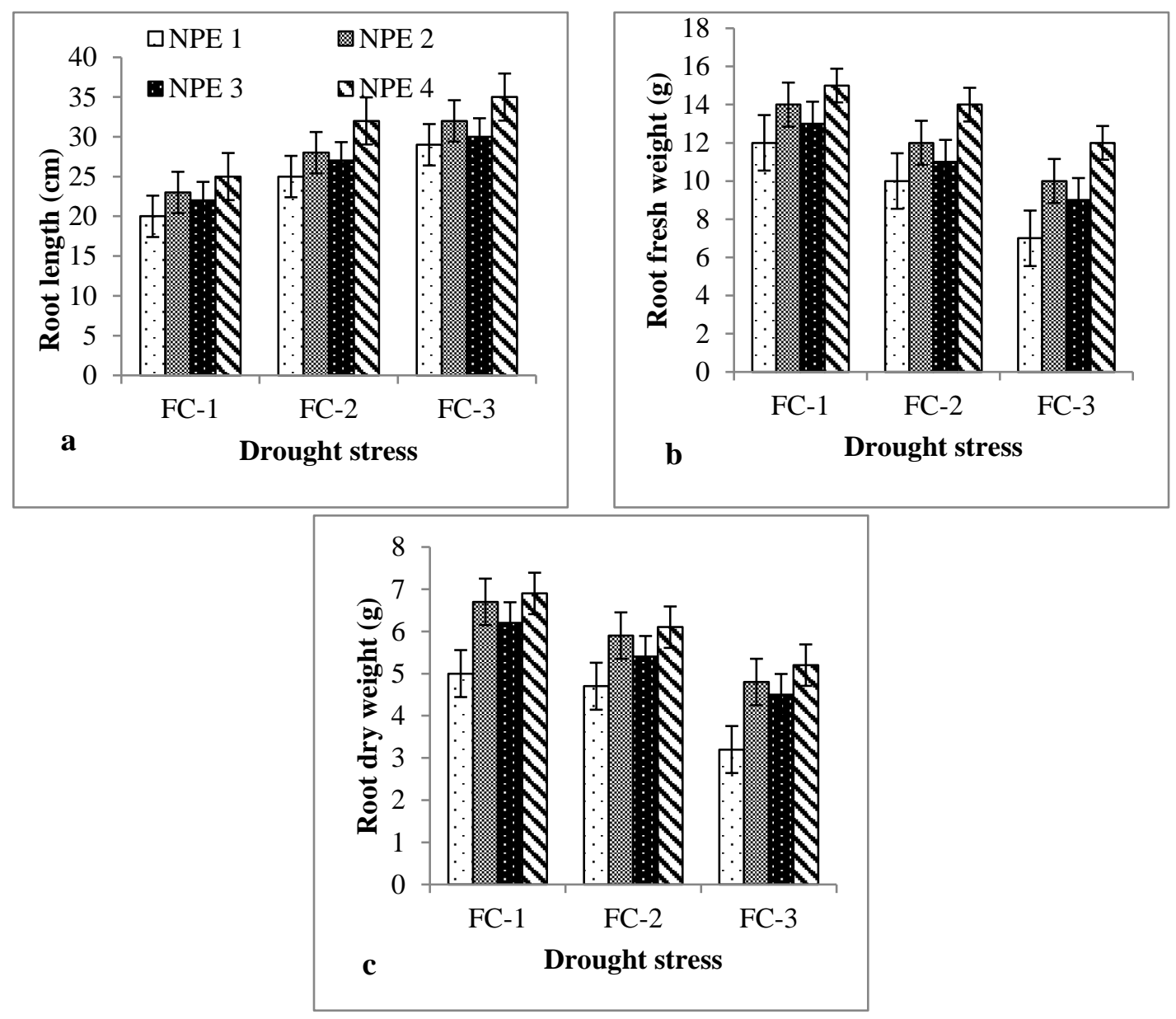

Figure 2. Effect of drought stress and natural plant extract (NPE) on root length, root fresh and dry weight accumulation. NPE 1; Water, NPE 2; Dianella ensata, NPE 3; Ambrosia dumosa, NPE 4; Moringa oleifera Lam. FC is field capacity that represent different levels of drought stress

\section{Discussion}

Drought is the most intimidating abiotic stress that affects growth and yield of field crops. Drought causes many damaging effects on crop morphological and physiological 
characteristics. It causes alteration in leaf morphology and gives rise to morpho-physiological changes that leads to impaired plant growth and grain development thus reducing plant yield (Alghabari and Ihsan, 2018). Because of drought stress the crop plants face disturbance in their osmotic balance, reduction in stomatal conductance, reduction in photosynthetic activities, lowering rate of membrane electron transport and also rate of evapotranspiration and loss of water from plants increases, and all these processes ultimately lead to reduction of growth and development thus reducing the final crop yield (Srivalli et al., 2003; Allahmoradi et al., 2011; Alghabari et al., 2014, 2015; Hussain et al., 2018). Crop plants under arid land conditions are subjected to water deficit stress especially at reproductive stage.

Barely growth and yield components were significantly affected by the extracts of the three natural plants (Dianella ensata, Ambrosia dumosa, Moringa oleifera Lam). These plants may have been containing growth stimulating molecules that may be present in any part of these plants; leaves, roots, stem, flower or fruit. Their presence in the root rhizosphere was demonstrated by many researchers (Bertin et al., 2003; Stock et al., 2019). Ihsan et al. (2015) reported growth inhibitory effects of different plants extract while Alghabari (2018) documented growth stimulatory effects of desert plants extract in mungbean crop. Application of plant based growth regulators is now considered a new agricultural field after its proven positive role in abiotic stress relief, economically viable and environment friendly. The role of the wild and natural plant extracts in reducing effects of drought impact on barley plant growth and yield may be due to their positive role in regulation of moisture supplies to crop plants, and in making nutrients more available to crop plants and enhancing the rate of photosynthesis.

Dianella ensifolia is an evergreen, perennial herb with grass-like leaves growing from a branched, gradually spreading rhizome. It can grow up to 1.5 metres tall, spreading at the roots to form quite large clumps. The plant is sometimes gathered from the wild for use as a medicine, pesticide and dye. Ambrosia dumosa is a highly branched shrub 20 to $90 \mathrm{~cm}$ in height. It is present in desert areas of the world. It becomes dormant during drought stress, losing all of its leaves to prevent water loss by transpiration. Moringa oleifera is a fast-growing, drought-resistant tree native to the Indian subcontinent. It is well adapted to arid lands of Saudi Arabia. A deciduous tree that can reaches a height of 10-12 m.

Many researchers have reported the growth stimulatory effects of different plants in field crops. Cowpea growth, yield and protein content were stimulated by the aqueous extract of Malva parviflora and Artemisia ludia (Lashin et al., 2013). Application of moringa leaf extract at two weeks interval after emergence has imporved maize plant height, fresh and dry weight, number of grains per cob and 100 grain weight (Biswas et al., 2016). Application of different plants extract controlled wheat leaf rust caused by Puccinia triticina and improved grain yield components such as 1000 grain weight (Shabana et al., 2017). The improvement in crops growth and yield by the foliar application of moringa plant aqueous extract suggested that it activated the antioxidants mechanism in plants to enable them to alleviate the oxidative damage caused by drought stress. It may have improved the physiological and molecular attributes in stressed plants that helped them to combat the adverse conditions of environmental stresses. Moringa oleifera is rich in amino acids, ascorbate, minerals and zeatin compounds known for their growth promoting potential (Latif and Mohamed, 2016). Chemical analysis of moringa leaf extract showed that GA4 is most likely in crosstalk with auxin is the major growth enhancer (Brockman et al., 2020). 
The ability of plants to resist drought stress and to improve their growth under drought through application of plant growth regulators is because of these extracts act as osmoregulators regulating osmosis in plant species, working as signaling agents, and hence reduces reactive oxygen species production and photorespiration. Overall, improvement in photosynthesis and in nutrient uptake enabled plants to resist and tolerate drought stress. The improvement of barley plants growth and yield under drought stress by application of Dianella ensata and Moringa oleifera Lam water extracts is due to the stimulatorry role of these extracts through increasing leaf osmotic process, plant water uptake, photo-assimilation and improvement of the plant antioxidant defense system. In future, studies are needed to identify wild plant species that have growth stimulatory effect under drought stress which can be used in field crops to tolerate and resist drought stresses. Reseach is also needed to identify and isolate the compounds that play an active role in drought stress mitigation.

\section{Conclusion}

Drought stress significantly affected barley growth and yield. The adversity of the drought stress increased with the decrease in field capacity. Application of wild plants (Dianella ensata, Ambrosia dumosa, Moringa oleifera Lam) aqueous extracts improved growth and yield of barley crop. The foliar applied extracts alleviated the negative effects of drought stress through improving crop growth and grain contributing traits that enabled the barley to effeciently absorb water and nutrients. The Moringa oleifera was the most promising wild plant extracts. It is recommended to screen and quantify the biomolecultes that have growth promoting effects through chromatographical processes and be produced as commercial commodities for utilization in plant drought tolerance and growth promotion under stressful environment.

Acknowledgements. This project was funded by the Deanship of Scientific Research (DSR) at King Abdulaziz University, Jeddah under grant number G:62-155-1440. The authors, therefore, acknowledge with thanks DSR for technical and financial support.

\section{REFERENCES}

[1] Abbasi, M. K., Mushtaq, A., Tahir, M. M. (2009): Cumulative effects of white clover residues on the changes in soil properties, nutrient uptake, growth and yield of maize crop in the sub-humid hilly region of Azad Jammu and Kashmir, Pakistan. - African Journal of Biotechnology 8: 10-20.

[2] Alghabari, F., Lukac, M., Jones, H. E., Gooding, M. J. (2014): Effect of Rht Alleles on the Tolerance of Wheat Grain Set to High Temperature and Drought Stress During Booting and Anthesis. - Journal of Agronomy and Crop Science 200: 36-45.

[3] Alghabari, F., Ihsan, M. Z., Hussain, S., Aishia, G., Daur, I. (2015): Effect of Rht alleles on wheat grain yield and quality under high temperature and drought stress during booting and anthesis. - Environmental Science and Pollution Research 22: 15506-15515.

[4] Alghabari, F. M. (2018): Foliar application of Saudi desert plants extract improved some mungbean agronomic traits under drought stress. - Journal of King Abdulaziz University 27: 21-29.

[5] Alghabari, F., Ihsan, M. Z. (2018): Effects of drought stress on growth, grain filling duration, yield and quality attributes of barley (Hordeum vulgare L.). - Bangladesh Journal of Botany 47: 421-428. 
[6] Allahmoradi, P., Ghobadi, M., Taherabadi, S., Taherabadi, S. (2011): Physiological aspects of mungbean (Vigna radiata $\mathrm{L}$.) in response to drought stress. - In: International conference on food engineering and biotechnology, IPCBEE 9: 272-275.

[7] Bertin, C., Yang, X., Weston, L. A. (2003): The role of root exudates and allelochemicals in the rhizosphere. - Plant and Soil 256: 67-83.

[8] Biswas, A. K., Hoque, T. S., Abedin, M. A. (2016): Effects of moringa leaf extract on growth and yield of maize. - Progressive Agriculture 27: 136-143.

[9] Bourne, J. K. (2009): The global food crisis-The end of plenty. - National Geographic, June 2009, pp. 26-59.

[10] Brockman, H. G., Brennan, R. F., van Burgel, A. (2020): The impact of phytohormone concentration in Moringa oleifera leaf extract on wheat yield and components of yield. Journal of Plant Nutrition 43: 396-406.

[11] Fahad, S., Bajwa, A. A., Nazir, U., Anjum, S. A., Farooq, A., Zohaib, A., Sadia, S., Nasim, W., Adkins, S., Saud, S., Ihsan, M. Z. (2017): Crop production under drought and heat stress: plant responses and management options. - Frontiers in plant science 8: 11471167.

[12] Fahad, S., Ihsan, M. Z., Khaliq, A., Daur, I., Saud, S., Alzamanan, S., Nasim, W., Abdullah, M., Khan, I. A., Wu, C., Wang, D. (2018): Consequences of high temperature under changing climate optima for rice pollen characteristics-concepts and perspectives. Archives of Agronomy and Soil Science 64: 1473-1488.

[13] FAO (2009): How to Feed the World in 2050. - Rome: High-Level Expert Forum.

[14] Fenta, B. A., Beebe, S. E., Kunert, K. J., Burridge, J. D., Barlow, K. M., Lynch, J. P., Foyer, C. H. (2014): Field phenotyping of soybean roots for drought stress tolerance. Agronomy 4: 418-435.

[15] Hussain, H. A., Hussain, S., Khaliq, A., Ashraf, U., Anjum, S. A., Men, S., Wang, L. (2018): Chilling and drought stresses in crop plants: implications, cross talk, and potential management opportunities. - Frontiers in Plant Science 9: 393.

[16] Ihsan, M. Z., Khaliq, A., Mahmood, A., Naeem, M., El-Nakhlawy, F., Alghabari, F. (2015): Field evaluation of allelopathic plant extracts alongside herbicides on weed management indices and weed-crop regression analysis in maize. - Weed Biology and Management 15: 78-86.

[17] Ihsan, M. Z., El-Nakhlawy, F. S., Fahad, S., Alzamanan, S. (2016a): Genotypes Selection on the basis of Periodic Performance-A Reliable Strategy to Maximize Crop Water Use Efficiency and Productivity in Arid Regions. - Annals of Arid Zone 55: 153-163.

[18] Ihsan, M. Z., El-Nakhlawy, F. S., Ismail, S. M., Fahad, S. (2016b): Wheat phenological development and growth studies as affected by drought and late season high temperature stress under arid environment. - Frontiers in Plant Science 7: 795-805.

[19] Lashin, G. M., Azab, A. A., Hussien, A. A., Anwar, A. E. (2013): Effects of plant extracts on growth, yield and protein content of cowpea (Vigna unguiculata L. Walp). Bangladesh Journal of Botany 42: 99-104.

[20] Latif, H. H., Mohamed, H. I. (2016): Exogenous applications of moringa leaf extract effect on retrotransposon, ultrastructural and biochemical contents of common bean plants under environmental stresses. - South African Journal of Botany 106: 221-231.

[21] Naeem, M., Naeem, M. S., Ahmad, R., Ihsan, M. Z., Ashraf, M. Y., Hussain, Y., Fahad, S. (2018): Foliar calcium spray confers drought stress tolerance in maize via modulation of plant growth, water relations, proline content and hydrogen peroxide activity. Archives of Agronomy and Soil Science 64: 116-131.

[22] Shabana, Y. M., Abdalla, M. E., Shahin, A. A., El-Sawy, M. M., Draz, I. S., Youssif, A. W. (2017): Efficacy of plant extracts in controlling wheat leaf rust disease caused by Puccinia triticina. - Egyptian Journal of Basic and Applied Sciences 4: 67-73.

[23] Srivalli, B., Sharma, G., Khanna-Chopra, R. (2003): Antioxidative defense system in an upland rice cultivar subjected to increasing intensity of water stress followed by recovery. - Physiologia Plantarum 119: 503-512. 
[24] Stock, S. C., Köster, M., Dippold, M. A., Nájera, F., Matus, F., Merino, C., Kuzyakov, Y. (2019): Environmental drivers and stoichiometric constraints on enzyme activities in soils from rhizosphere to continental scale. - Geoderma 337: 973-982.

[25] Yasmeen, A., Basra, S. M. A., Ahmad, R., Wahid, A. (2012): Performance of late sown wheat in response to foliar application of Moringa oleifera Lam. leaf extract. - Chilian Journal of Agricultural Research 72: 92-97.

[26] Zhang, J. (2011): China's success in increasing per capita food production. - Journal of Experimental Botany 62: 3707-371. 